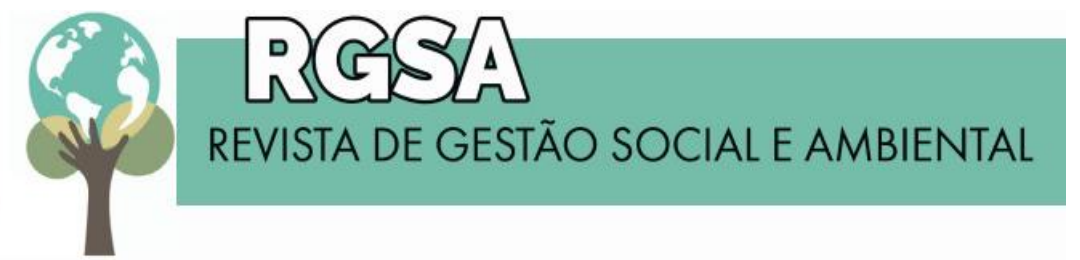

RGSA - Revista de Gestão Social e Ambiental ISSN: $1981-982 \mathrm{X}$

Data de submissão: 11/02/2021

Data de aceite: 29/09/2021

DOI: https://doi.org/10.24857/rgsa.v15.2646

Organização: Comitê Científico Interinstitucional

Editora Chefe: Eliana Andréa Severo

Avaliação: Double Blind Review pelo SEER/OJS

\title{
ANÁLISE CONFIRMATÓRIA DE COMPETÊNCIAS GERENCIAIS PARA O DESENVOLVIMENTO SUSTENTÁVEL
}

\author{
Fabiana Pinto de Almeida Bizarria ${ }^{1}$ \\ Flávia Lorenne Sampaio Barbosa ${ }^{2}$ \\ Sérgio Luiz Corrêa dos Santos $^{3}$ \\ Paulo Guilherme Oliveira ${ }^{4}$
}

\section{RESUMO}

Objetivo: identificar fatores a ssocia dos à s competências gerencia is fa vorá veis ao Desenvolvimento Sustentá vel.

Referencial teórico: Para tanto, recorreu-se ao levantamento de categorias realizadas por Bizarria et. al. (2020), em estudo qualitativo desenvolvido com base em entrevistas com administradores e gestores organizacionais inseridos no mercado de trabalho.

Método: Seguindo as categorias a presentadas; Relações interpessoais, Inovação sustentável, Análise multidimension a 1, Decisão sustentável, Estratégias sustentáveis e Racionalidade-filosofia, realizou-se a elaboração de um questionário, que obteve como respondentes 207 profissionais atuantes em empresas brasileiras como administradores/gestores de unidades de trabalho ou organização.

Resultados e conclusão: Com a escala inicial de 36 itens, a Análise Fatorial Exploratória (AFE), em 5 momentos, resultou em 25 itens, a nalisados por meio da Análise Fatorial Confirmatória (AFC), que, em três etapas, resultou em 18 itens distribuídos em 6 fatores em um modelo com ajustes modera damente satisfatórios.

Implicações da pesquisa: Foram observados ajustes satisfatórios na maioria dos índices de ajustamento (absoluto, relativo e de parcimônia): os parâmetros de $\chi^{2}$ [(196,422, p 0,00), ajustado, pois < 3], RMSEA [(0,056), ajuste aceitável, pois < 0,08], CFI $[(0,881)$, ajuste aceitável, pois > 0,8], TLI $[(0,846)$ ajuste aceitável, pois > 0,8], NFI [(0,759), ajustado, pois < 0,8], PRATIO [(0,771), ajustado, pois $>0,6]$, PCFI $[(0,680)$, ajuste aceitável, pois $>0,6]$, PNFI [(0,585) ajuste modera damente a ceitável, pois < 0,6], AIC [309,226], menor valor entre os modelos, então, mais ajustado.

Originalidade/valor: Por fim, foram definidas 6 categorias (Estratégias, Orientação para Resultado, Inovação, Análise, Liderança e Valores, todos na perspectiva do Desenvolvimento Sustentável) com seus respectivos temas presentes em 18 variá veis do instrumento, representando o modelo final.

Palavras-chave: Competências gerenciais, Desenvolvimento Sustentável, Decisão Sustentável, Análise Multidimensional, Estratégias Sustentá veis.

\footnotetext{
${ }^{1}$ Doutorado em Administração pela Universidade de Fortaleza (UNIFOR), Ceará (Brasil). Email: bianapsq@ hotmail.com Orcid: https://orcid.org/0000-0001-8365-8593

${ }^{2}$ Doutorado em Administração de Empresas pela Universidade de Fortaleza (UNIFOR), Ceará (Brasil). Orcid: https://orcid.org/0000$\underline{0002-4804-9538}$

${ }^{3}$ Mestre em Administração pela Universidade Vale do Itajaí - UNIVALI, Santa Catarina (Brasil). Professor da Faculdade Luciano Feijão, Ceará (Brasil). Orcid: https://orcid.org/0000-0002-7010-2323

${ }^{4}$ Graduando em Administração - Faculdade Luciano Feijão, Ceará (Brasil). Orcid: https://orcid.org/0000-0002-3605-3994
}

\begin{tabular}{|l|l|l|l|l|l|}
\hline Rev. Gest. Soc. Ambient. & São Paulo (SP) & v.15 & p.01-20 & e02646|2021. \\
\hline
\end{tabular} 
Bizarria, F. P. de A., Barbosa, F. L. S., Santos, S. L. C. dos, \& Oliveira, P. G. (2021). Análise Confirmatória de Competências Gerenciais para o Desenvolvimento Sustentável.

\title{
CONFIRMATORY ANALYSIS OF MANAGERIAL COMPETENCIES FOR SUSTAINABLE DEVELOPMENT
}

\begin{abstract}
Purpose: A research aimed to identify factors associated with managerial competencies favorable to Sustainable Development. For that, we used the survey of categories evaluated by Bizarria et al (2020), in a qualitative study developed based on choice with administrators and organizational managers inserted in the labor market.
\end{abstract}

Method/design/approach: Following as categories choose; Interpersonal relations, Sustainable innovation, Multidimensional analysis, Sustainable decision, Sustainable strategies and Rationality-philosophy, prepared the preparation of a questionnaire, which received 207 professionals working in Brazilian companies as respondents as managers / managers of work units or organizations.

Results and conclusion: With the initial scale of 36 items, the Exploratory Factor Analysis (AFE), in 5 moments, resulted in 25 items, which were concluded through the Confirmatory Factor Analysis (AFC), which, in three stages, resulted in 18 items distributed in 6 factors in a model with moderately satisfactory adjustments.

Research implications: Satisfactory adjustments were observed in most adjustment indices (absolute, relative and parsimony): the parameters of $\chi 2$ [(196,422, p 0.00), adjustment, because $<3]$, RMSEA [(0.056), acceptable adjustment, because <0.08], CFI [ $(0.881)$, acceptable adjustment, because >0.8], TLI [(0.846) acceptable adjustment, be cause >0.8], NFI [(0.759), adapts, because <0.8 ], PRATIO [(0.771), travel, because >0.6], PCFI [(0.680), acceptable adjustment, because> 0.6], PNFI [(0.585) moderately acceptable adjustment, because <0.6], AIC [309.226], lower value between models, then, more applicable.

Originality/value: Finally, 6 categories were defined (Strategies, Result Orientation, Innovation, Analysis, Leadership and Values, all from the perspective of Sustainable Development) with their respective themes present in 18 variables of the instrument, representing the finalmodel.

Keywords: Managerial Competencies, Sustainable Development, Sustainable Decision Making, Multidimensional Analysis, Sustainable Strategies.

\section{INTRODUÇÃO}

A amplitude dos assuntos ambientais e suas relações com as organizações, que desde o final dos anos de 1960, período em que a sociedade despertou para os perigos provenientes da poluição e degradação ambiental, vem assumindo destaque na agenda de pesquisadores da administração (Leonidou \& Leonidou, 2011). Estudos, ainda, reforçam a relevância na integração das dimensões da sustentabilidade com as teorias das organizações no sentido de ampliar possibilidades de gestão promotoras da melhoria das condições de vida em coletividade (Sousa \& Ribeiro, 2013), na lógica de pensar soluções que possam refletir no desenvolvimento sustentável para o século XXI (Guimarães \& Fontoura, 2012), impulsionando a incorporação de temas emergentes relacionados à sustentabilidade nas produções científicas nacionais e internacionais (Gallon et al., 2008).

É preciso, portanto, além de defender, com base na leitura de Froehlich (2014), a necessidade da preservação da vida, as empresas, para se manterem no mercado atual, devem considerar não somente os fatores econômicos (lucro), mas também privilegiar a performance ambiental (planeta) e social (pessoas). Dessa forma, deve-se discutir não somente à questão da preservação da vida e do meio ambiente, mas possibilidades de ampliar o desenvolvimento do

\begin{tabular}{|l|l|l|l|l|l|}
\hline Rev. Gest. Soc. Ambient. & São Paulo (SP) & v.15 & p.01-20 & e02646 & 2021. \\
\hline
\end{tabular} 
Bizarria, F. P. de A., Barbosa, F. L. S., Santos, S. L. C. dos, \& Oliveira, P. G. (2021). Análise Confirmatória de Competências Gerenciais para o Desenvolvimento Sustentável.

campo empresarial, sendo, por sua vez, essencial, haja vista se observar que os critérios econômicos ainda prevalecem na decisão sobre a adoção de práticas sustentáveis (Borges, Chotoe \& Varela, 2014).

Destaca-se, portanto, o interesse de pesquisas que relacionem entre estratégias corporativas e a sustentabilidade, em geral, sustentadas pelas dimensões econômica, social e ambiental (Chabowski \& Mena, Gonzalez-Padron, 2011, Jabbour, Santos \& Barbieri, 2008;

Luca et al., 2014), bem como as que fundamentam questões operacionais como; gestão, tecnologia e urbanização (Schubert \& Láng, 2005), além de ações que possam fortalecer o desenvolvimento econômico (empresarial) e social (políticas públicas) (Rosa \& Ensslin, 2007).

Por um lado, o foco dado às pesquisas brasileiras reforçam as dimensões social, ambiental e econômica, ou Triple Bottom Line (TBL), como, por exemplo, nos estudos de Elkington (2012) (Schubert \& Láng, 2005, Rosa \& Ensslin, 2007, Gallon et al., 2008; Chabowski; Mena; GonzalezPadron, 2011, Jabbour, Santos \& Barbieri, 2008, Sousa \& Ribeiro, 2013), autores, também, ampliam a definição para outras dimensões, como, por exemplo; Sachs I.; Porter, M. E., Glaser, B., Van Bellen, H. M. ou Bellen, H. M. V., Tachizawa, T., Barbieri, J. C.; Costa, F. de A.; Elkington, J.; Hart, S. L. A.; Abramovay, R. Ao passo que, internacionalmente, as pesquisas têm revisitado preocupações mais abrangentes, como; ontologia, fatores para adoção de iniciativas de sustentabilidade; avaliação de desempenho; impactos sociais e ou ambientais e relatórios de sustentabilidade (Silveira \& Petrini, 2018). Nesse curso, apresenta-se o desenho de uma pesquisa que sugere a necessidade de problematizar os desafios ambientais, face às concepções de aprendizagem e desenvolvimento de competências capazes de elucidar outros olhares sobre a relação do homem com o meio ambiente (Gonçalves-Dias, Herrera \& Cruz, 2013), guiando-se por compromissos dos atores sociais com a preservação da vida, convocando reflexões em torno de suas práticas. Considera-se, portanto, o papel fundamental que as organizações desempenham para o alcance de padrões satisfatórios de sustentabilidade para o planeta, sendo as competências caminho para ampliar o escopo das práticas favoráveis a esse alcance. Assim, o tema competências para sustentabilidade vai ao encontro de ampliar estudos sobre sustentabilidade nos processos formativos, como sugerem Ghoshal (2005), Springet (2005) e Shivastava (2010), especificamente, para o campo da gestão.

Ao passo que, para a definição de competências, aspectos contextuais do trabalho e as mudanças sociais são importantes de serem consideradas (Zarifian, 2001), assim, as dimensões que envolvem o conceito precisa manter-se em constante análise, haja vista a configuração de processos formativos capazes de fortalecer o desenvolvimento laboral e das organizações, também, se modificam, face aos desafios que as organizações vivenciam na sociedade, como, por exemplo; mudanças no mercado, crises sociais e eventos que exigem pensamento e ação como a transformação tecnológica em curso (Zarifian, 2001, Brandão, 2010) e crises de saúde pública, como a que se verifica na situação de pandemia decorrente do novo Coronavírus (SARS-CoV-2), considerada um dos maiores problemas sanitários do século (OIT, 2020).

Ante esse contexto e, na perspectiva do desafio da configuração de práticas voltadas à sustentabilidade, as formulações de Sachs (2007, 2009) avançam na compressão dos atores e de seus compromissos, o que sugere possibilidades de definição de competências para o desenvolvimento sustentável, sendo, este, o objetivo dessa pesquisa. Para tanto, recorre-se à Sachs (2007, 2009) em função de suas concepções assumirem os seguintes princípios: satisfação das necessidades básicas; solidariedade com as gerações futuras; participação da população envolvida; preservação dos recursos naturais e do meio ambiente em geral; elaboração de um sistema social, garantindo emprego; segurança social e respeito a outras culturas; e programas de educação. No que

\begin{tabular}{|l|l|l|l|l|l|}
\hline Rev. Gest. Soc. Ambient. & São Paulo (SP) & v.15 & p.01-20 & e02646 & 2021. \\
\hline
\end{tabular} 
Bizarria, F. P. de A., Barbosa, F. L. S., Santos, S. L. C. dos, \& Oliveira, P. G. (2021). Análise Confirmatória de Competências Gerenciais para o Desenvolvimento Sustentável.

tangem as competências, em especial, as gerenciais, estão associadas aos gerentes, sendo suas ações reflexo de suas atividades no contexto laboral, o que implica no desenvolvimento e expressão dos papéis organizacionais que assumem (Quinn et al., 2003). De forma específica, as competências gerenciais situam um conjunto de atributos inter-relacionados que, desenvolvidas pelo gestor em situações cotidianas, favorecem a obtenção de resultados, conforme as estratégias organizacionais definidas (Ruas, 2005). Portanto, essas competências se apresentam como fundamentais à prática profissional do administrador/gestor, haja vista que este assume responsabilidades, cada vez mais abrangentes, ante à organização de processos e técnicas voltadas ao desempenho contributivo ao desenvolvimento sustentável.

Então, para responder ao seguinte problema: quais fatores associados às competências gerenciais são favoráveis ao desenvolvimento sustentável?, recorreu-se ao levantamento de categorias realizadas por Bizarria et al. (2020), no sentido da elaboração de um instrumento de pesquisa, tratado por meio das etapas da Análise Fatorial Exploratória (AFE) e Análise Fatorial Confirmatória (AFC). Por certo, atende-se a existência de lacunas conforme aponta Froehlich (2014) e avança, quantitativamente, na pesquisa iniciada por Bizarria et al. (2020). No ensejo, direciona objetivos e estratégias organizacionais no alinhamento do desempenho de pessoas e/ou equipes em prol de uma agenda sustentável, pois, entende-se que, as competências gerencias podem contribuir no sentido do fortalecimento de práticas no caminho do desenvolvimento de habilidades, conhecimentos, atitudes e valores convergentes com a performance ambiental (planeta) e social (pessoas). Nesse sentido, convocar conhecimento agregador à definição de competências gerenciais em contexto de desenvolvimento sustentável, ainda, confere relevância à perspectiva do aprendizado e adaptação de longo prazo que ocorrem em um indivíduo ou grupo em resposta às demandas ambientais (Berry, 1997). Assim, estudo dessa natureza podem contribuir com agendas governamentais e corporativas em torno do processo de mudança cultural da sociedade rumo à sustentabilidade. Para além de ensejar re(olhares) em prol da promoção de capacidades dinâmicas no que tange à trajetória, posição e processos organizacionais, face à visão de futuro, formação e auto-responsabilidade, alinhados de forma construtiva para o processo de desenvolvimento sustentável (Pospichil et al., 2020).

\section{COMPETÊNCIAS GERENCIAIS PARA O DESENVOLVIMENTO SUSTENTÁ VEL}

As competências podem ser compreendidas em sua expressão individual, ante à capacidade de agir, mobilizar, integrar, se responsabilizar, na consecução de suas atividades laborais, podendo expressar-se na capacidade de agregar valor econômico (desempenho/vantagem competitiva), e valor social (indivíduo/sociedade) (Fleury \& Fleury, 2001); e, organizacional, que envolve o saberfazer coletivo, em uma articulação de recursos organizacionais (pessoas, tecnologia, estrutura de gestão) (Prahalad \& Hamel, 1990).

Com o avanço dos estudos sobre competências, o contexto vai assumindo maior ênfase ao representar a "competência" associada à ideia de compartilhamento, em rede, em processo de comunicação (Fleury \& Fleury, 2001, 2004, Dutra, 2004), na integração e transferência de competências individuais referidas ao contexto profissional (Le Boterf, 2003). Nesse caminho, surge o interesse pela definição de 'competências gerenciais', definidas como as que envolvem conhecimentos, habilidades e atitudes esperados dos que exercem funções de administração/gestão (Borges-Andrade \& Bittencourt, 2004, Spencer \& Spencer, 1993, Freitas \& Odelius, 2018, Alves

\begin{tabular}{|l|l|l|l|l|l|}
\hline Rev. Gest. Soc. Ambient. & São Paulo (SP) & v.15 & p.01-20 & e02646 & 2021. \\
\hline
\end{tabular} 
Bizarria, F. P. de A., Barbosa, F. L. S., Santos, S. L. C. dos, \& Oliveira, P. G. (2021). Análise Confirmatória de Competências Gerenciais para o Desenvolvimento Sustentável.

Filho, Silva \& Muzzio, 2019), pela compreensão de sua influência no desempenho de equipes de trabalho e, consequentemente, sobre os resultados da organização (Brandão et al., 2012)

Por se referir às práticas gerenciais, essas competências situam a capacidade de mobilização de conhecimentos, habilidades, atitudes e valores, como recursos (tangíveis e intangíveis) na obtenção de resultados (Alves Filho, Silva \& Muzzio, 2019), considerando o contexto, os recursos disponíveis e a estratégia da organização (Freitas \& Odelius, 2018). As competências gerenciais mais reconhecidas na literatura são: orientação para resultados; habilidade com pessoas e equipes; liderança, coordenação e motivação; habilidade com mudanças, inovações e capacidade de adaptação situacional; comunicação; planejamento; atitudes e valores; gestão do conhecimento e da aprendizagem; conhecimentos e habilidades técnicas; e org anização, alocação e mobilização de recursos (Freitas, 2016).

Válido ressaltar que, a própria dinâmica de cada cenário institucional e, de cada contexto, pode modular a própria definição do que sejam competências gerenciais, bem como o número e as definições de suas dimensões (Ferreira \& Paiva, 2017). Assim, pensar a formação de competências gerenciais favoráveis ao desenvolvimento sustentável confere a capacidade de refletir e analisar criticamente, bem como de resolver problemas, por meio de um conjunto de conhecimentos, habilidades e atitudes no trabalho que gera desempenho profissional (Boog, 1991, Durand, 2000), face ao contexto interno (organização) e externo (social, político e cultural).

Dito isso, tem-se no reconhecimento do valor do conhecimento e no compromisso do alcance de melhor qualidade social, ambiental e econômica, a utilização de competências gerenciais para se atingir os resultados desejados do desenvolvimento sustentável (Dzhengiz \& Niesten, 2019). Nesse sentido, se tem uma probabilidade maior de tomar decisões sobre o que deve ou não ser feito, e sob que circunstâncias, projetos com foco nesse desenvolvimento são/serão realizados (Hassan, 2020). A exemplo, estudos têm fornecido classificações diferentes para competências circunscritas à sustentabilidade, tais como: comunicação, liderança, orientação para o desenvolvimento, flexibilidade, influência, motivação, trabalho em equipe, orientação para as realizações, foco na qualidade, foco no cliente, planejamento, inovação e tomada de decisão (Fanelli et al., 2020, Hassan, 2020).

Tal questão, reforça que, além do desafio de definir competências gerenciais referidas ao contexto externo à organização, é preciso considerar o desenvolvimento, destas, e levá-lasà discussão para a formação acadêmica (Gondim, 2002). Em se tratando, especificamente, da formação em administração, pode-se observar que, na Resolução n. 4, de 13 de julho de 2005, já são apresentadas a necessidade de uma análise crítica sobre problemas, bem como consciência das implicações éticas do exercício profissional (Demajorovic \& Martão, 2014). Embora o que se denomina "ética" possa seguir variadas conotações, pode-se agregar, a este estudo, a ideia de que o administrador deve estar atento às consequências de sua ação, bem como exercitar a capacidade de propor soluções com base em análises contextualizad as.

Para referenciar a pesquisa apresentada em relação a uma definição de competências gerenciais, recorreu-se ao estudo de Quinn et al. (2003), que apresenta quatro modelos de gestão diferentes, entre si, que dão base para as ações modernas gerenciais: (1) o modelo de relações humanas, que foca na abertura, participação, moral e compromisso; (2) o modelo de sistemas abertos, que se destina à adaptação, ao crescimento, à aquisição de recursos e à inovação; (3) o modelo de metas racionais, que se relaciona à direção, à produtividade, à realização e à clareza de objetivos; e, por fim, (4) o modelo de processos internos, que prioriza o controle, o gerenciamento de informações, a documentação e a estabilidade (Quinn et al., 2003).

\begin{tabular}{|l|l|l|l|l|l|l|}
\hline Rev. Gest. Soc. Ambient. & São Paulo (SP) & v.15 & p.01-20 & e02646 & 2021. \\
\hline
\end{tabular} 
Bizarria, F. P. de A., Barbosa, F. L. S., Santos, S. L. C. dos, \& Oliveira, P. G. (2021). Análise Confirmatória de Competências Gerenciais para o Desenvolvimento Sustentável.

Com referência ao modelo de competências gerenciais apresentado por Quinn et al. (2003), define-se a proposição de Sachs (2007, 2009) sobre desenvolvimento sustentável, na perspectiva de ampliar a análise econômica, social e ambiental à esfera cultural, política, territorial e ecológica. Por compreender a complexidade da relação da sociedade com um projeto de desenvolvimento, o autor internaliza a dimensão política de participação pública, ao passo que defende a necessidade de selecionar/identificar/criar técnicas capazes de otimizar a utilização de recursos sintonizada com a ecologia.

No entanto, as competências para o desenvolvimento sustentável foram identificadas por meio do cruzamento dos critérios de desenvolvimento sustentável com base em Sachs $(2007,2009)$ com o quadro de valores competitivos elaborado por Quinn et al. (2003), realizado na pesquisa qualitativa desenvolvida por Bizarria et al. 2020 (Figura 1).

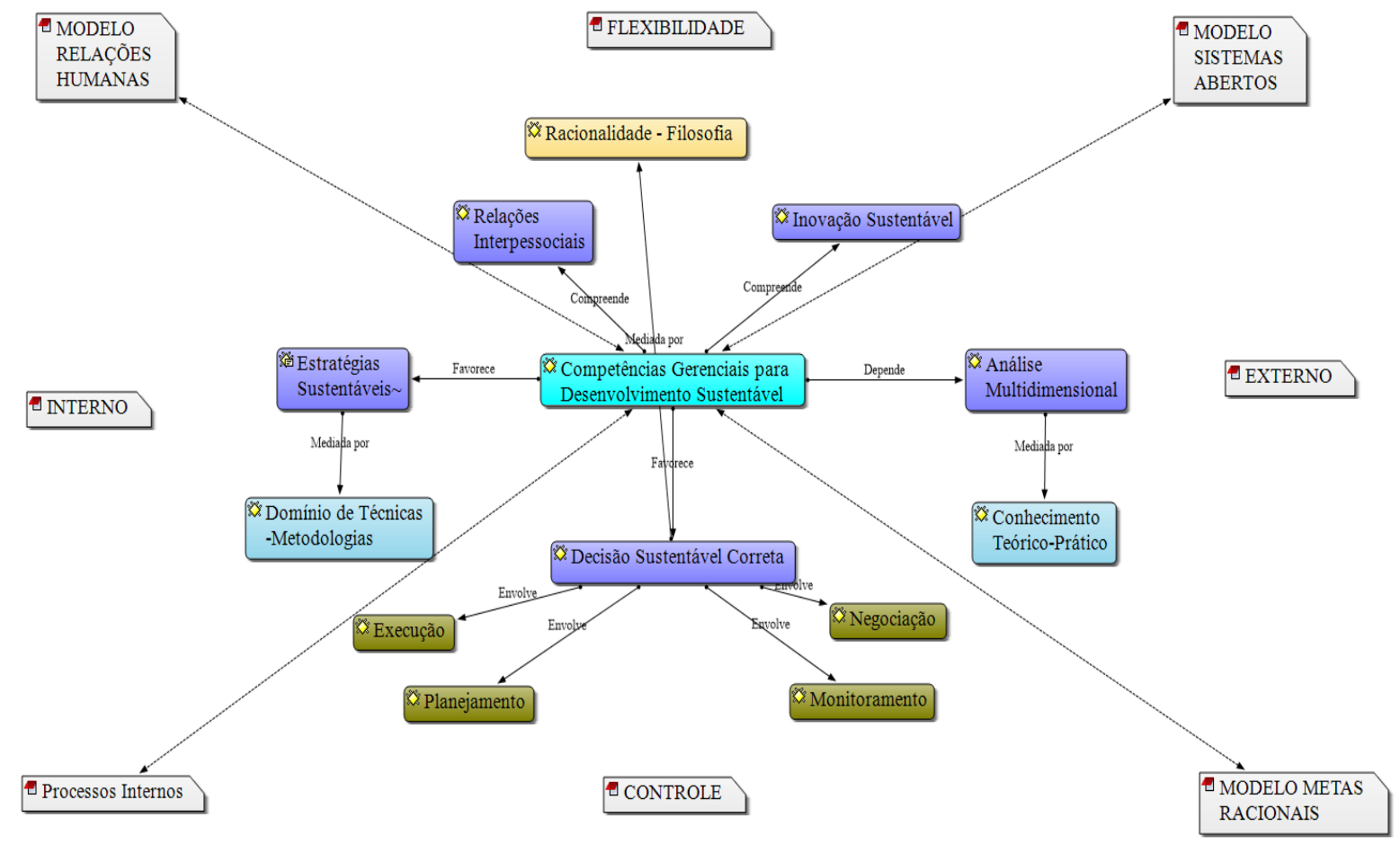

Figura 1. Categorias relaciona das às Competências Gerenciais para o Desenvolvimento Sustentável Fonte: Bizarria et al. (2020).

Em suma, emergiram-se 6 (seis) categorias, com suas respectivas subcategorias; (i) estratégias sustentáveis: (ii) decisão sustentável correta; (iii) relações interpessoais, (iv) inovação sustentável; (v) análise multidimensional e (vi) racionalidade-filosofia.

\section{METODOLOGIA}

A pesquisa de teor descritivo do tipo levantamento ou survey, é desenvolvida conforme abordagem quantitativa (Richardson, 1999, Collis \& Hussey, 2005), com dados coletados em uma amostra probabilística da população de 207 administradores/ gestores brasileiros que, responderam um questionário elaborado para essa pesquisa, com 36 itens (formulário eletrônico elaborado no

\begin{tabular}{|l|l|l|l|l|l|}
\hline Rev. Gest. Soc. Ambient. & São Paulo (SP) & v.15 & p.01-20 & e02646 & 2021. \\
\hline
\end{tabular} 
Bizarria, F. P. de A., Barbosa, F. L. S., Santos, S. L. C. dos, \& Oliveira, P. G. (2021). Análise Confirmatória de Competências Gerenciais para o Desenvolvimento Sustentável.

Google Docs), após convite realizado em redes sociais (bola de neve), com a manifestação voluntária em reposta ao Termo de Consentimento Livre de Esclarecido (TCLE).

$\mathrm{O}$ instrumento de coleta de dados utilizado foi elaborado seguindo categorias apresentadas pelo estudo de Bizarria et al. (2020), no caso; Relações interpessoais, Inovação sustentável, Análise multidimensional, Decisão sustentável correta, Estratégias sustentáveis e Racionalidade-filosofia, desenvolvido com amparo na teoria de Quinn et al. (2003) sobre competências gerenciais e nas dimensões apresentadas no conceito de desenvolvimento sustentável defendido por Sachs (2007, 2009).

Para a realização do teste empírico, os missings foram tratados pelo procedimento de substituição dos valores ausentes pela média. Os outliers foram considerados como observações extraordinárias inexplicáveis por se tratar de percepções subjetivas dos respondentes (Corrar, Paulo \& Dias Filho, 2014). A pesquisa teve proporção de 5,75, considerando 207 respondentes para 36 variáveis. Esse quantitativo amostral atende a recomendação de Hair et al. (2009), que sugere o mínimo de cinco vezes mais observações do que o número de variáveis.

Na sequência, adotou-se a estratégia da Análise Fatorial Exploratória (AFE) que objetiva a identificação de dimensões existentes em um conjunto de fenômenos, com base em uma estrutura subjacente e que pode ser expressa em fatores para melhor representar os dados (Hair Jr. et al., 2009). Para analisar os resultados da AFE, foram realizados os testes Kaiser-Meyer-Okin e o de esfericidade de Bartlett, e Rotated Commponente Matrix (Hair et al. 2009) e o Alfa de Cronbach, por meio do software Statistical Package for the Social Sciences (SPSS), versão 20.

Em seguida, foi realizada a Análise Fatorial Confirmatória (AFC), usada para fornecer um teste confirmatório de uma teoria de mensuração (Hair Jr. et al., 2009; Byrne, 2010; Marôco, 2014), realizada por meio do programa computacional Analysis of Moment Structures (AMOS) (versão 22.0).

Para análise do Modelo de AFC, foram considerados os índices de ajustamento presentes no output do modelo no software AMOS. Em ralação aos índices, os considerados mais relevantes por Byrne (2010) e Marôco (2014) são: os índices de ajustes absolutos, responsáveis pela avaliação da qualidade do modelo per se, sem a comparação com outros modelos, sendo representados, nesse estudo, pelo Chi-quadrado $\left(\chi^{2}\right)$ e o Root Mean Square Error of Approximation (RMESEA). Os índices de ajustamentos relativos, que avalia a qualidade em relação a outros modelos, representados pelo Normed Fit Index (NFI), o Comparative Fit Index (CFI) e o Tucker-Lewis Index (TLI). Por fim, são analisados os índices de ajustamento de parcimônia, obtidos por meio da correção dos índices relativos por um fator de penalidade associado à complexidade do modelo, representados pelo Parsimony ratio-PRATIO (razão de parcimônia inicial), o Parsimony CFI (penaliza o CFI), o Parsimony NFI (penaliza o NFI) e o Akaike information criterion (AIC).

\section{APRESENTAÇÃO DOS RESULTADOS}

$\mathrm{Na}$ sequência, são apresentados resultados da Análise Fatorial Exploratória (AFE), e, na sequência, a Análise Fatorial Confirmatória (AFC).

\begin{tabular}{|l|l|l|l|l|l|}
\hline Rev. Gest. Soc. Ambient. & São Paulo (SP) & v.15 & p.01-20 & e02646 & 2021. \\
\hline
\end{tabular} 
Bizarria, F. P. de A., Barbosa, F. L. S., Santos, S. L. C. dos, \& Oliveira, P. G. (2021). Análise Confirmatória de Competências Gerenciais para o Desenvolvimento Sustentável.

\subsection{Análise Fatorial Exploratória}

Inicialmente, foram realizados os testes Kaiser-Meyer-Okin (Kaiser-Meyer-Olkin Measure of Sampling Adequacy (KMO) e o de esfericidade de Bartlett (tabela 1) como forma de referendar o modelo em estudo.

Tabela 1 - Teste de esfericidade de Barlett

KMO and Bartlett's Test

\begin{tabular}{l|l|r}
\hline \multicolumn{2}{|l|}{ Kaiser-Meyer-Olkin Mea sure of Sampling Adequacy. } & $\mathbf{6 9 1}$ \\
\hline \multirow{3}{*}{ Bartlett's Test of Sphericity } & Approx. Chi-Square & 1458,958 \\
\cline { 2 - 3 } & df & 300 \\
\cline { 2 - 3 } & Sig. &, 000 \\
\hline
\end{tabular}

Fonte: dados da pesquisa

Nota: tabela extraída do output do software SPSS

O teste de esfericidade de Barlett (tabela 1) demonstra se o valor elevado dessa estatística de teste favorece a rejeição da hipótese nula (Malhotra, 2012), bem como indica se existe relação suficiente entre os indicadores para aplicação da análise fatorial (Bezerra, 2012). A estatística quiquadrado aproximada é 1458, 958, com 300 graus de liberdade, significativa ao nível de 0,000 . Para ser possível a análise fatorial, se recomenda que o valor de Sig. (teste de significância) não ultrapasse 0,005 (Bezerra, 2012). A medida de adequação da amostra, Kaiser-Meyer-Olkin (KMO), por sua vez, pode ser interpretada com as seguintes orientações: 0,80 muito adequado; 0,70 ou acima, adequado; 0,60 ou acima, pouco adequado; 0,50, inadequado (Hair et al., 2005). Observa-se, portanto, que a amostra se apresenta no limite da ad equabilidade $(0,691)$

$\mathrm{Na}$ sequência, foi solicitada a extração de 6 fatores, considerando o estudo de Bizarria et al. (2020), com a exclusão de cargas fatoriais abaixo de 0,4, bem como variáveis que carregaram em mais de um fator, observando o critério da raiz latente e uma solução que explique entre $50 \%$ e $60 \%$ da variância total (e em alguns casos até menos), posto serem aceitáveis em pesquisas exploratórias no campo das ciências sociais (Hair et al. 2005; Malhotra, 2012).

Na primeira extração de fatores, foram excluídas da análise as variáveis V11 (0,517-Fator 2; 0,417-Fator 4), V15 (0,623-Fator 1; 0,465-Fator 6). Ao realizar a segunda extração por meio da AFE, foram excluídas a V34 (0,52-Fator 3; 0,443-Fator 5). Após terceira AFE, foram excluídas a V5 (0.412-Fator 3; -0,431-Fator 2), a V21 (0,441-Fator 2; 0,426-Fator 3). Com a quarta AFE, saíram da análise a V12 (0,560 - Fator 2; 0,402 - Fator 5), V20 (0,463 - Fator 3; 0,427 - Fator 4); V7 (0,437 - Fator 2; 0,530 - Fator 5). A quinta e última AFE gerou a exclusão da V18 (0,506 Fator 2; 0,503 - Fator 4), V17 (0,428 - Fator 1; 0,472-Fator 5), V24 (0,621 - Fator 4; -0,427 Fator 6). Com a última extração, restaram 25 variáveis distribuídas em 6 fatores (tabela 2), com a variância explica de 52,775\%.

Tabela 2 - Análise Fatorial Exploratória - Solução Final

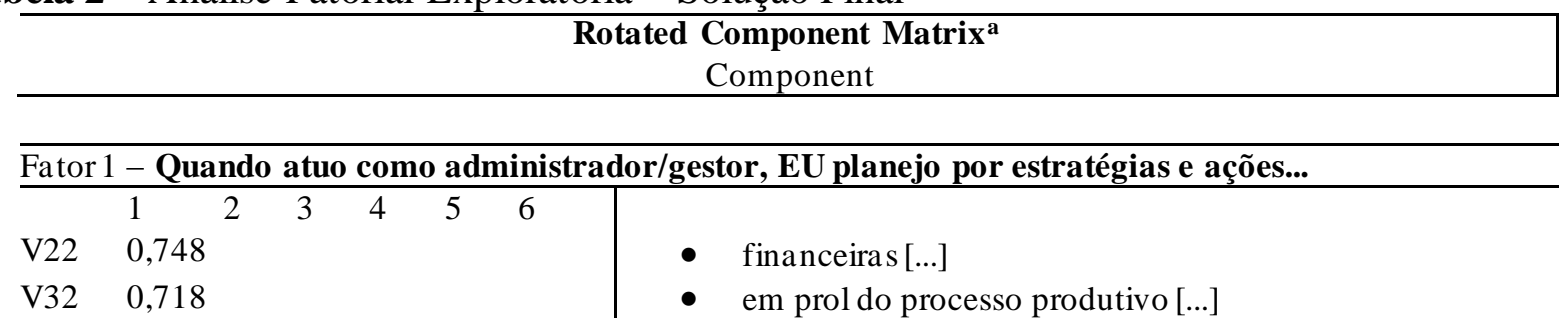

\begin{tabular}{|l|l|l|l|l|l|}
\hline Rev. Gest. Soc. Ambient. & São Paulo (SP) & v.15 & p.01-20 & e02646 & 2021. \\
\hline
\end{tabular} 
Bizarria, F. P. de A., Barbosa, F. L. S., Santos, S. L. C. dos, \& Oliveira, P. G. (2021). Análise Confirmatória de Competências Gerenciais para o Desenvolvimento Sustentável.

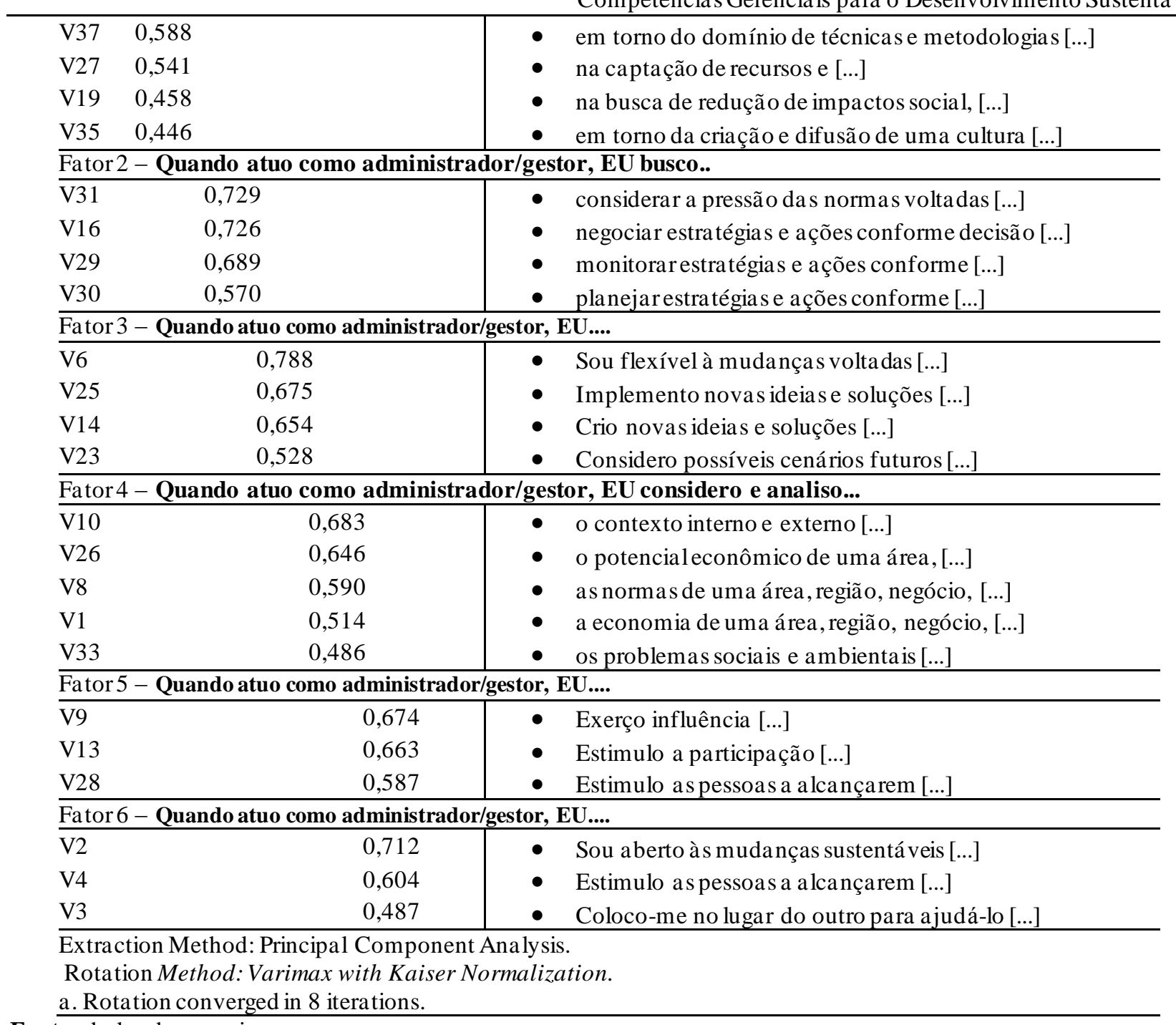

Fonte: dados da pesquisa

Nota: tabela extraída do output do software AMOS/SPSS

Nota: foram inseridas na tabela parte da descrição dos itens dos instrumentos que restaram na solução final.

Na sequência, para avaliar a confiabilidade da pesquisa, utilizou-se o Alfa de Cronbach, modelo de consistência interna baseada na correlação entre as variáveis, cuja ideia principal é que estas devem medir o mesmo constructo e, assim, serem altamente intercorrelacionados (Hair et al., 1999). Para Streiner (2003), o valor mínimo aceitável para o alfa é 0,70; abaixo desse valor a consistência interna da escala utilizada é considerada baixa. Para Malhotra (2012), considera-se Confiabilidade Muito Baixa (Alfa $<0,3)$, Baixa $(0,3<$ Alfa $<0,6)$, Moderada $(0,6<$ Alfa $<0,75)$. Alta $(0,75<A l f a<0,9)$ e Muito Alta $(A l f a>0,9)$. No entanto, o valor máximo esperado é 0,90; acima deste valor, pode-se considerar que há redundância ou duplicação (Hair et al., 2009). 
Bizarria, F. P. de A., Barbosa, F. L. S., Santos, S. L. C. dos, \& Oliveira, P. G. (2021). Análise Confirmatória de Competências Gerenciais para o Desenvolvimento Sustentável.

Tabela 3 - Componente Matrix

\begin{tabular}{c|c|c}
\hline \multirow{2}{*}{ Solução Final AFE } & \multicolumn{2}{|c}{ Reliability Statistics } \\
\cline { 2 - 3 } & Cronbach's Alpha & N of Items \\
\hline Fator 1 & $\mathbf{8 1 9}$ & $\mathbf{2 5}$ \\
\hline Fator 2 & 0,749 & 6 \\
\hline Fator 3 & 0,689 & 4 \\
\hline Fator 4 & 0,684 & 4 \\
\hline Fator 5 & 0,573 & 5 \\
\hline Fator 6 & 0,486 & 3 \\
\hline
\end{tabular}

Fonte: dados da pesquisa

Nota: tabela extraída do output do software AMOS/SPSS

Assim, com base na confiabilidade do conjunto de variáveis (25 Alfa > 0,819), e, com o resultado da AFE, realizou-se a AFC, que, de acordo com Marôco (2014, p. 180), “[...] é geralmente usada para avaliar a qualidade de ajustamento de um modelo de medida teórico à estrutura correlacional observada entre as variáveis manifestas (itens)". Além disso, recorre-se à AFC quando se busca um quadro confirmatório, por meio da análise estrutural da teoria, combinando aspectos da análise fatorial e de regressão múltipla, permitindo estudar relações de dependência, simultaneamente (Byrne, 2010). Nessa etapa, a análise dos dados foi realizada por meio do programa computacional Analysis of Moment Structures (AMOS) (versão 22.0).

\subsection{Análise Fatorial Confirmatória}

Segundo Marôco (2014), na especificação de um modelo de AFC, o número de fatores é estabelecido, a priori, de acordo com teorias e estudos anteriores. Dessa forma, foi dada sequência ao estudo de Bizarria et al. (2020), na proposição de um modelo baseado em 6 fatores, cuja extração por meio da AFE permitiu levar à AFC variáveis com cargas fatoriais maiores de 0,4 , sem duplicidade de cargas entre fatores.

Para validação do pressuposto da normalidade multivariada (Tabela 4), a análise preliminar revelou que nenhuma variável apresentou valores de $S k$ e $K u$ com violações severas à distribuição Normal $(|S k|<3$ e $|K u|<10$ (tabela 5). Ao passo que em uma distribuição normal $S k=K u=0$, quando as variáveis apresentam $S k$ e $K u$ próximas a 0 , pode-se pressupor a normalidade multivariada e, com isso, a verificação de atendimento do pressuposto, a AFC pode produzir resultados eficientes e consistentes (Marôco, 2014).

Tabela 4 - Teste de Normalidade

\begin{tabular}{|c|c|c|c|c|c|c|}
\hline \multicolumn{7}{|c|}{ Assessment of normality (Group number 1) } \\
\hline Variable & $\min$ & $\max$ & skew & c.r. & kurtosis & c.r. \\
\hline V10 & 2 & 5 & $-0,67$ & $-4,019$ & $-0,408$ & $-1,225$ \\
\hline V26 & 1 & 5 & $-1,081$ & $-6,485$ & 0,292 & 0,876 \\
\hline V1 & 1 & 5 & $-1,044$ & $-6,263$ & 1,5 & 4,499 \\
\hline V33 & 1 & 5 & $-1,3$ & $-7,799$ & 1,622 & 4,865 \\
\hline V31 & 1 & 5 & $-0,814$ & $-4,883$ & 1,553 & 4,659 \\
\hline V16 & 1 & 5 & $-0,419$ & $-2,517$ & $-0,692$ & $-2,077$ \\
\hline V30 & 1 & 5 & $-0,641$ & $-3,845$ & $-0,183$ & $-0,548$ \\
\hline V22 & 1 & 5 & $-0,166$ & $-0,999$ & $-1,066$ & $-3,197$ \\
\hline
\end{tabular}

\begin{tabular}{|l|l|l|l|l|l|}
\hline Rev. Gest. Soc. Ambient. & São Paulo (SP) & v.15 & p.01-20 & e02646 & 2021. \\
\hline
\end{tabular} 
Bizarria, F. P. de A., Barbosa, F. L. S., Santos, S. L. C. dos, \& Oliveira, P. G. (2021). Análise Confirmatória de Competências Gerenciais para o Desenvolvimento Sustentável.

\begin{tabular}{lllrrrr}
\hline V32 & 1 & 5 & $-0,338$ & $-2,026$ & $-0,822$ & $-2,465$ \\
V37 & 1 & 5 & $-0,368$ & $-2,209$ & $-0,523$ & $-1,57$ \\
V35 & 1 & 5 & $-0,694$ & $-4,162$ & 0,227 & 0,681 \\
V2 & 1 & 5 & $-0,035$ & $-0,208$ & $-0,712$ & $-2,136$ \\
V4 & 1 & 5 & $-0,034$ & $-0,205$ & $-1,195$ & $-3,584$ \\
V13 & 1 & 5 & $-0,785$ & $-4,708$ & 0,586 & 1,758 \\
V28 & 1 & 5 & $-0,204$ & $-1,225$ & $-0,662$ & $-1,985$ \\
V6 & 1 & 5 & $-0,377$ & $-2,261$ & $-0,572$ & $-1,717$ \\
V25 & 1 & 5 & $-0,032$ & $-0,19$ & $-0,609$ & $-1,827$ \\
V23 & 1 & 5 & $-0,883$ & $-5,299$ & 0,425 & 1,275 \\
\hline Multivariate & & & & 59,197 & 16,212 \\
\hline
\end{tabular}

Nota: O maior valor de $S k|-1,3|$, é <3 |, e o maiorvalores $K u|1,553|$,é < 10 .

Fonte: dados da pesquisa

Nota: tabela extraída do output do software AMOS/SPSS

Para a reespecificação do modelo, foram consideradas as sugestões presentes nos índices de modificação para melhorar o ajustamento, quando foram correlacionadas os erros de variáveis pertencentes a um mesmo fator (e6 <-> e5; e12 <->13); seguindo da retirada de itens da análise que, conforme índice de modificação, saturam em fatores diferentes: V27 e V19 - Fator 1; V29 - Fator 2; V14 - Fator 3; V8 - Fator 4; V9 - Fator 5; V3 - Fator 6. A Figura 2 apresenta o modelo modificado com a AFC após as reespecificação.

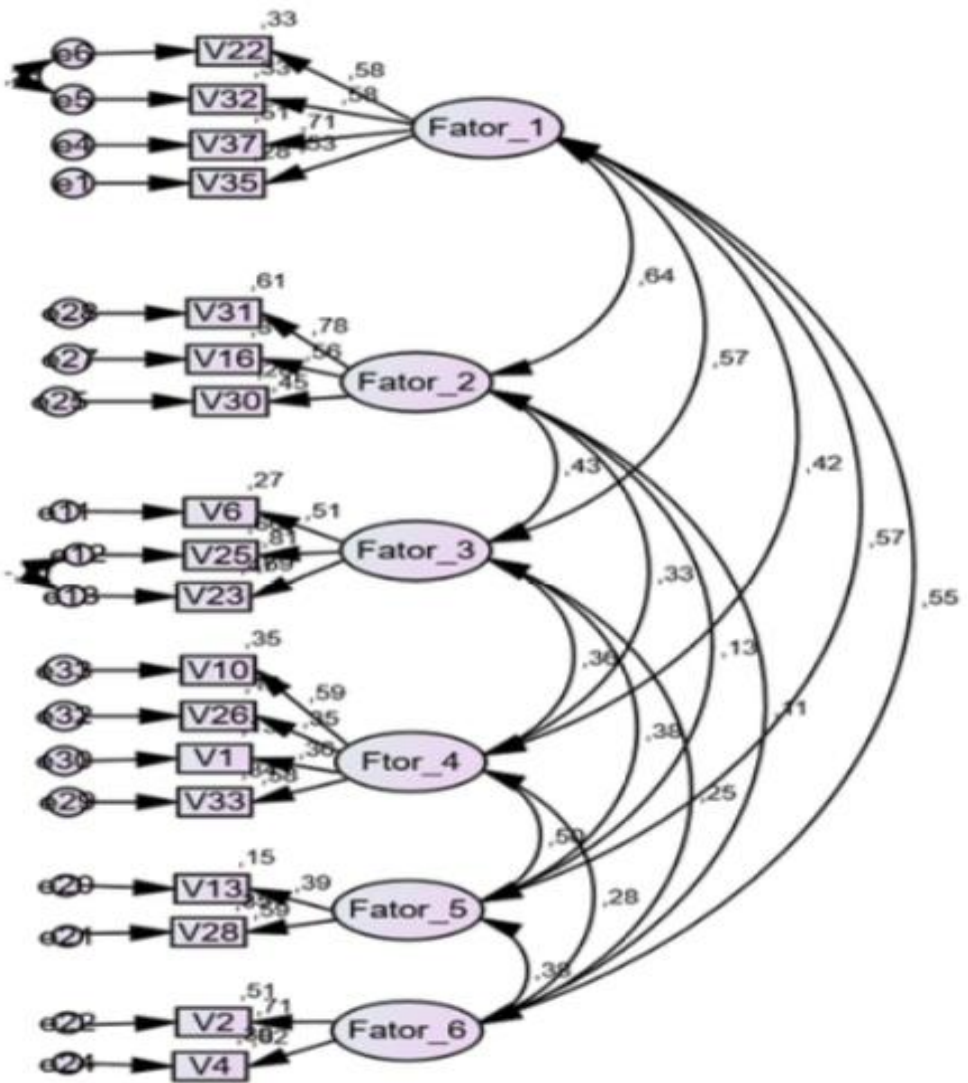

Figura 2. Modelo Modificado 3 - AFC Solução Final

Fonte: dados da pesquisa

Nota: desenho extraído do output do software AMOS/SPSS

\begin{tabular}{|l|l|l|l|l|l|}
\hline Rev. Gest. Soc. Ambient. & São Paulo (SP) & v.15 & p.01-20 & e02646 & 2021. \\
\hline
\end{tabular} 
Bizarria, F. P. de A., Barbosa, F. L. S., Santos, S. L. C. dos, \& Oliveira, P. G. (2021). Análise Confirmatória de Competências Gerenciais para o Desenvolvimento Sustentável.

Após a especificação do modelo inicial, os dados demonstraram bom ajustamento do modelo, em referência aos índices de ajustamento recomendado para a avaliação do modelo: 'ajustes absolutos' $\left[\chi^{2}\right.$ (ajustado, se $<3$, aceitável se $<5$ e inaceitável se $>5$ ); RMESEA ajustado, se $<0,05$, aceitável se $<0,08$ e inaceitável se $>0,08$ ]; 'ajustes relativos' [CFI (ajuste perfeito $=1$, aceitável $>0,8$, ajustado $>0,9$ ); TLI (ajuste perfeito $=1$, aceitável $>0,8$, ajustado $>0,9$ ); NFI (ajustado <0,8)] e 'ajustes de parcimônia' [Parsimony PRATIO (ajustado>0,6); Parsimony CFI (aceitável $>0,6$, ajustado $>0,8$ ) e Parsimony NFI > (aceitável >0,6, ajustado >0,8); AIC, quanto menor o valor, mais ajustado o modelo)]. Conforme Tabela 5, pode-se inferir, com base na avaliação da qualidade do ajustamento do modelo, que o modelo reespecificado III, demostra ajustes moderadamente satisfatórios.

Tabela 5 - Ajustes estruturais do modelo da pesquisa

\begin{tabular}{l|c|c|c|c|c|c|c|c|c}
\hline & \multicolumn{2}{|c|}{ Ajuste Absoluto } & \multicolumn{3}{c|}{ Ajuste Relativos } & \multicolumn{3}{c}{ Ajuste de Parcimônia } \\
\hline Modelos & Chi-quadrado & RMSEA & CFI & TLI & NFI & PRATIO & PCFI & PNFI & AIC \\
\hline M. 1 & $644,470(p 0,00)$ & 0,083 & 0,686 & 0,638 & 0,577 & 0,867 & 0,594 & 0,500 & 824,470 \\
M. Modificado 1 & $299,472(p$ 0,00) & 0,067 & 0,803 & 0,756 & 0,679 & 0,805 & 0,647 & 0,547 & 453,472 \\
M. Modificado 2 & $250,226(p 0,00)$ & 0,063 & 0,839 & 0,796 & 0,717 & 0,789 & 0,662 & 0,566 & 338,422 \\
M. Modificado 3 & $\mathbf{1 9 6 , 4 2 2 ( p ~ 0 , 0 0 )}$ & $\mathbf{0 , 0 5 6}$ & $\mathbf{0 , 8 8 1}$ & $\mathbf{0 , 8 4 6}$ & $\mathbf{0 , 7 5 9}$ & $\mathbf{0 , 7 7 1}$ & $\mathbf{0 , 6 8 0}$ & $\mathbf{0 , 5 8 5}$ & $\mathbf{3 0 9 , 2 2 6}$ \\
\hline
\end{tabular}

Nota: o modelo modificado 3, após reespecificarão, apresentou Degrees of freedom (189 - 71): 118

Nota: tabela extraída do output do software AMOS/SPSS

Fonte: dados da pesquisa

Com base na Tabela 6, observa-se que o ajustamento (absoluto, relativo e de parcimônia) do modelo segue os parâmetros de $\chi^{2}[(196,422$, p 0,00), ajustado, pois < 3], RMSEA [(0,056), ajuste aceitável, pois < 0,08], CFI $[(0,881)$, ajuste aceitável, pois $>0,8]$, TLI $[(0,846)$ ajuste aceitável, pois $>0,8]$, NFI $[(0,759)$, ajustado, pois < 0,8], PRATIO [(0,771), ajustado, pois >0,6], PCFI [(0,680), ajuste aceitável, pois > 0,6], PNFI [ $(0,585)$ ajuste moderadamente aceitável, pois < 0,6], AIC [309,226], menor valor entre os modelos, então, mais ajustado.

Todos os pesos de regressão padronizados $(\beta)$ são significativos ao nível de significância ( $<<0,01)$. Os valores de C.R. (Critical Ratio) estão acima dos valores de referência (C.R $>|1,96|$ ) conforme a tabela 6 .

Tabela 6 - Pesos de Regressão para o Modelo Modificado 3 - AFC Solução Final

\begin{tabular}{|c|c|c|c|c|c|c|c|}
\hline \multicolumn{8}{|c|}{ Regression Weights: (Group number 1 - Default model) } \\
\hline & & & Estimate & S.E. & C.R. & $\overline{\mathbf{P}}$ & Label \\
\hline V23 & <--- & Fator_3 & 1 & & & & \\
\hline V25 & $<---$ & Fator_3 & 1,192 & 0,208 & 5,722 & $* * *$ & par_16 \\
\hline V6 & $<---$ & Fator_3 & 0,797 & 0,194 & 4,117 & $* * *$ & par_17 \\
\hline V28 & $<---$ & Fator_5 & 1 & & & & \\
\hline V13 & $<--$ & Fator_5 & 0,614 & 0,192 & 3,203 & 0,001 & par_18 \\
\hline V4 & $<--$ & Fator_6 & 1 & & & & \\
\hline V2 & $<--$ & Fator_6 & 0,94 & 0,206 & 4,552 & $* * *$ & par_19 \\
\hline V35 & $<--$ & Fator_1 & 1 & & & & \\
\hline V37 & $<---$ & Fator_1 & 1,492 & 0,228 & 6,546 & $* * *$ & par_20 \\
\hline V32 & $<---$ & Fator_1 & 1,275 & 0,219 & 5,828 & $* * *$ & par_21 \\
\hline V22 & $<--$ & Fator_1 & 1,368 & 0,235 & 5,828 & $* * *$ & par_22 \\
\hline V30 & $<--$ & Fator_2 & 1 & & & & \\
\hline
\end{tabular}

\begin{tabular}{|l|l|l|l|l|l|}
\hline Rev. Gest. Soc. Ambient. & São Paulo (SP) & v.15 & p.01-20 & e02646 & 2021. \\
\hline
\end{tabular} 
Bizarria, F. P. de A., Barbosa, F. L. S., Santos, S. L. C. dos, \& Oliveira, P. G. (2021). Análise Confirmatória de Competências Gerenciais para o Desenvolvimento Sustentável.

\begin{tabular}{l|l|l|c|c|c|c|c}
\hline V16 & $<---$ & Fator_2 & 1,417 & 0,293 & 4,845 & $* * *$ & par_23 \\
V31 & $<---$ & Fator_2 & 1,422 & 0,28 & 5,085 & $* * *$ & par_24 \\
V33 & $<---$ & Ftor_4 & 1 & & & & \\
V1 & $<---$ & Ftor_4 & 0,594 & 0,165 & 3,592 & $* * *$ & par_25 \\
V26 & $<---$ & Ftor_4 & 0,778 & 0,22 & 3,536 & $* * *$ & par_26 \\
V10 & $<---$ & Ftor_4 & 0,89 & 0,194 & 4,589 & $* * *$ & par_27 \\
\hline
\end{tabular}

Fonte: Dados da pesquisa

Nota: $* * * \mathrm{p} \leq 0,001$.

Nota: No quadro “Intercepts:(Group number 1 - Default model)", todas os valores são significativos a $\mathrm{p} \leq 0,001$.

\section{DISCUSSÃO}

Antes de defender competências gerenciais para o desenvolvimento sustentável é importante ressaltar a posição apresentadas por essa pesquisa, conforme leitura de Ferreira e Paiva (2017). As competências gerenciais possuem uma condição de análise institucional e contextual, ou seja, mesmo que sejam apresentadas dimensões favoráveis ao desenvolvimento sustentável, é preciso considerar como estas podem ser exploradas e desenvolvidas com base nos objetivos e metas organizacionais e percursos institucional, bem como considerar o contexto social, político, econômico e cultural em que essas competências serão manifestas.

Especificamente, em relação aos dados, a discussão apresenta configuração de seis categorias ao estudo das competências gerenciais, anteriormente apresentadas por Bizarria et al. (2020), em um estudo qualitativo. Com a matriz fatorial rotacional, confirmada pela AFC, parte-se para uma interpretação dos fatores com suporte das teorias que deram ensejo à elaboração dos fatores e do instrumento (Malhotra, 2012). Para a definição de cada fator, foram consideradas o teor dos itens em consonância com as teorias de Quinn et al. (2003) e de Sachs (2007, 2009) (quadro1).

Quadro 1 - Fatores extraídos da AFC e suas definições

\begin{tabular}{|c|c|c|}
\hline Fatores & Temas das variáveis & Definições \\
\hline 1. Estra tégias para o DS & $\begin{array}{l}\text { Suporte financeiro (V22) } \\
\text { Processo produtivo (V32) } \\
\text { Técnica e Metodologias (V37) } \\
\text { Criação e Difusão (V35) }\end{array}$ & $\begin{array}{l}\text { Definição de estratégia s com garantias de suporte } \\
\text { financeiro, com ênfase na capacidade do processo } \\
\text { produtivo por meio da adoção de técnicas e } \\
\text { metodologias que possam promover o } \\
\text { desenvolvimento sustentável. }\end{array}$ \\
\hline $\begin{array}{l}\text { 2. Orientação para } \\
\text { Resultados -DS }\end{array}$ & $\begin{array}{l}\text { Pressão normativa (V31) } \\
\text { Negocia ção (V16) } \\
\text { Planejamento(V30) }\end{array}$ & $\begin{array}{l}\text { Orientação decisória com referência na legislação } \\
\text { ambiental e que articule negociação e } \\
\text { planejamento. }\end{array}$ \\
\hline 3. Inovação o DS & $\begin{array}{l}\text { Flexibilida de a mudanças (V06) } \\
\text { Novas ideias e soluções (V 14) } \\
\text { Cenários (V23) }\end{array}$ & $\begin{array}{l}\text { Flexibilidade em torno de mudanças inovadoras, } \\
\text { com incorporação de novas ideias, soluções e } \\
\text { análise prospectiva na perspectiva do } \\
\text { desenvolvimento sustentável. }\end{array}$ \\
\hline 4. Análise para o DS & $\begin{array}{l}\text { Contex to interno e externos (V10) } \\
\text { Potencial econômico (V26) } \\
\text { Economia de uma área, região ou } \\
\text { negócio (V01) } \\
\text { Problemas sociais e ambientais } \\
\text { (V33) }\end{array}$ & $\begin{array}{l}\text { Capacidade de análise sobre contexto interno e } \\
\text { externo a organização, bem como do potencial } \\
\text { econômico e a economia atual em articulação com } \\
\text { as problemáticas sociais a mbientais e presentes. }\end{array}$ \\
\hline 5. Liderança para o DS & $\begin{array}{l}\text { Participação (V13) } \\
\text { Incentivo a o desenvolvimento (V } \\
28)\end{array}$ & $\begin{array}{l}\text { Capacidade de liderança com investimento em } \\
\text { participação e incentivo ao desenvolvimento } \\
\text { individuais organizacionale coletivo. }\end{array}$ \\
\hline 6. Valores para o DS & $\begin{array}{l}\text { Abertura a mudanças (V02) } \\
\text { Alcance de objetivos comuns }\end{array}$ & $\begin{array}{l}\text { Difusão de valores voltados à abertura e à } \\
\text { mudanças, bem como ao alcance de objetivos }\end{array}$ \\
\hline
\end{tabular}

\begin{tabular}{|l|l|l|l|l|l|}
\hline Rev. Gest. Soc. Ambient. & São Paulo (SP) & v.15 & p.01-20 & e02646|2021. \\
\hline
\end{tabular} 
Bizarria, F. P. de A., Barbosa, F. L. S., Santos, S. L. C. dos, \& Oliveira, P. G. (2021). Análise Confirmatória de Competências Gerencia is para o Desenvolvimento Sustentável.

\begin{tabular}{|l|l|l|}
\hline & (V04) & $\begin{array}{l}\text { coletivos, com garantia do bem-estar da } \\
\text { coletividade. }\end{array}$ \\
\hline
\end{tabular}

Fonte: elaborado pelos autores

O Fator 1, responsável por 11,39\% da variância explicada na AFE. Restaram na AFC quatro variáveis relacionadas, a saber; estratégicas financeiras, processo produtivo, domínio de técnicas e metodologias, e criação e difusão de cultura voltada à sustentabilidade, sendo o aspecto financeiro o mais ressalto, ao passo que a variável apresenta a maior carga fatorial na AFE (V22, 0,748).

Ao passo que a dimensão informa o que os estudos demonstram sobre a prevalência de critérios econômicos na adoção de práticas sustentáveis (Borges, Chotoe \& Varela, 2014), nessa pesquisa representado pela resposta dada em torno dos critérios adotados para o planejamento de ações e práticas. Adicionalmente, importa destacar que os demais aspectos fazem parte do que Sachs (2007, 2009) denomina redirecionamento tecnológico, ao passo que pressupõe a incorporação de técnicas ao processo produtivo ambientalmente referenciado, para isso, necessário à adoção de uma cultura favorável ao desenvolvimento de novas metodologias e implementação junto aos processos organizacionais. São, portanto, presentes no que Quinn et al. (2003) denomina modelo de metas racionais, com ênfase na perspectiva da produção. Sobre o Fator 2, responsável por 9,55\% da variância explicada na AFE expressa a orientação de gestores no curso do desenvolvimento sustentável. Os aspectos abordados nessa dimensão, com base nas três variáveis confirmadas na AFC, envolvem a pressão normativa, a negociação e o planejamento capazes de promover a sustentabilidade. Nesse fator, a pressão normativa expressa maior carga fatorial na AFE (V31, 0,729), ao lado da negociação (V16 (0,726), o que se pode inferir a partir do impacto da legislação ambiental sobre a institucionalização da orientação pró sustentabilidade, expressas, por exemplo, na ideia de licenciamentos, imposto verde, ICMS ecológico, como apresentam, Froehlich (2014) e Lizuka e Peçanha (2014). Ainda, evidencia-se o papel da negociação e planejamento em associação à pressão normativa, ao passo que sugere a necessidade de sustentar a orientação gerencial no caminho do desenvolvimento sustentável na perspectiva do modelo de competências gerenciais baseado nas metas racionais com a abordagem diretiva de Quinn et al. (2003).

O Fator 3, responsável por 9,35\% da variância explicada na AFE, assume a confirmação de três variáveis na AFC, com ênfase na flexibilidade e mudanças, assunção de novas ideias e soluções e, ainda, consideração sobre cenários prospectivos. Para esse fator, a AFE apresenta a variável da flexibilidade e mudança como de maior carga fatorial (V6, 0,788), o que se releva necessário quando se apresenta ao contexto do desenvolvimento sustentável a busca de inovações que sejam ambiental e socialmente benignas (Hansen, Grosse-Dunker \& Reichwald, 2009), e, com isso, ser a inovação um meio significativo de apoio à sustentabilidade (Froehlich, Mello \& Engelman, 2017). O Fator 3, portanto, evidencia aspectos relacionados ao modelo dos sistemas abertos, com foco na ideia de gestão inovadora (Quinn et al. 2003), além do direcionamento para a promoção das subcapacidades dinâmicas para sustentabilidade (Pospichil et al., 2020). Em relação ao Fator 4, responsável por $8,12 \%$ da variância explicada na AFE, confere representação pela AFC das variáveis relacionadas à análise do contexto interno e externo, do potencial econômico, da economia atual de uma dada área, região ou organização e consideração dos problemas sociais e ambientais. Para esse fator, a AFE apresenta a variável análise contextual como de maior carga fatorial (V10, 0,683), ao lado o potencial econômico (V26, 0,646). Na articulação dos temas presentes no fator, pode considerar a capacidade de monitoramento e coordenação da gestão, em relação aos sistemas internos (Quinn et al. (2003), que objetive promover o desenvolvimento sustentável. Tal questão, vai ao encontro do que Demajorovic e Martão (2014) sugerem para a

\begin{tabular}{|l|l|l|l|l|l|}
\hline Rev. Gest. Soc. Ambient. & São Paulo (SP) & v.15 & p.01-20 & e02646 & 2021. \\
\hline
\end{tabular} 
Bizarria, F. P. de A., Barbosa, F. L. S., Santos, S. L. C. dos, \& Oliveira, P. G. (2021). Análise Confirmatória de Competências Gerenciais para o Desenvolvimento Sustentável.

atuação de administradores/ gestores que é de analisar, eticamente, as consequências das ações gerenciais. Mesmo ante à consideração da economia atual e do potencial econômico, os problemas sociais e ambientais entram em discussão.

Para o Fator 5, a AFE gerou 7,99\% de variância explicada, que, na AFC confirmou duas variáveis relacionadas à participação nos processos e incentivo ao desenvolvimento das pessoas envolvidas. Com cargas fatoriais bem próximas (V13, 0,663; V28, 0,587), são aspectos presentes da concepção de liderança, ao passo que se apresenta na perspectiva da facilitação e mentoria de processos, situados no modelo de relações humanas (Quinn et al.(2003). Nesse caminho, sugere-se a afirmação de Berry (1997) quando ressalta a importância do incentivo à aprendizagem para poder dar respostas às problemáticas ambientais, bem como promover liderança frente às mudanças mais contextuais da sociedade.

Por fim, o Fator 6, na AFE teve como variância explicada o valor de 6,35\%. Na AFC confirmou a presença de duas variáveis relacionadas à abertura a mudanças e ao alcance de objetivos comuns. Com cargas fatoriais próximas (V2, 0,663; V4, 0,604), os temas presentes convocam consideração sobre o que Sachs (2007, 2009) apresenta de forma diferenciada em teorização, no caso, integra a ideia valores, crenças, costumes à concepção do desenvolvimento sustentável. Ou seja, para que o gestor situe sua prática na perspectiva do desenvolvimento sustentável, evidencia-se a necessidade de aberturas às mudanças, o que a própria ideia de inovação sustentável reforça, mas, ainda, considera o sistema de valores presentes de maneira a buscar objetivos que promovem o bem coletivo. Sugere-se a concepção de valores ao Fator pelo tema bem comum, posto evidenciar o que Schwartz (1992) apresenta como valor de 'universalismo', quando a meta motivacional é a procura do bem-estar de todos, bem como se apresenta a teoria do desenvolvimento sustentável de Sachs (2007, 2009). Para tanto, na visão de Pospichil et al. (2020), a educação constante se faz necessária e, oportuna, para a efetivação de práticas organizacionais sustentáveis, por meio da formação, auto-responsabilidade e visão de futuro.

\section{CONCLUSÃO}

Com a finalidade de identificar fatores associados às competências gerenciais favoráveis ao Desenvolvimento Sustentável, a pesquisa buscou, por meio de análise estatística, ampliar o levantamento de categorias realizadas por Bizarria et al. (2020). Com isso, o instrumento, inicialmente, foi construído com 36 (trinta e seis) itens, com referência nas competências gerenciais proposto por Quinn et al. (2003) e nas dimensões do desenvolvimento sustentável definidos por Sachs (2007, 2009), e, logo após, com a participação de 207 (duzentos e sete) respondentes, foi analisado por meio de Análise Fatorial Exploratória (AFE) e Análise Fat orial Confirmatória (AFC).

Com a extração de fatores, por meio da AFE, em 5 (cinco) etapas, resultou em uma solução final com 25 (vinte e cinco) variáveis distribuídas em 6 (seis) categorias apreciadas por meio da AFC. Esta, após processo de reespecificação, seguindo os índices de modificação, resultou em 18 (dezoito) variáveis no terceiro modelo proposto, após correlação entre erros de variáveis pertencentes a um mesmo fator. Tem-se, portanto, como categorias determinadas pelo estudo; (i) Estratégias/Desenvolvimento Sustentável (DS); (ii) Orientação para Resultado/DS; (iii) Inovação/ DS; (iv) Análise/ DS; (v) Liderança/ DS; e, por fim, (vi) Valores/ DS, definidas com base na compreensão dada às variáveis confirmadas no modelo teórico ajustado por meio de AFC.

Não se limitam as possibilidades de definições relacionadas às competências gerenciais para o desenvolvimento sustentável, mas apresenta um quadro de referência com base na articulação dos

\begin{tabular}{|l|l|l|l|l|l|l|}
\hline Rev. Gest. Soc. Ambient. & São Paulo (SP) & v.15 & p.01-20 & e02646 & 2021. \\
\hline
\end{tabular} 
Bizarria, F. P. de A., Barbosa, F. L. S., Santos, S. L. C. dos, \& Oliveira, P. G. (2021). Análise Confirmatória de Competências Gerenciais para o Desenvolvimento Sustentável.

estudos de Quinn et al. (2003), Sachs (2007, 2009) e Bizarria et al. (2020). Com esse quadro, outros estudos podem empreender avanços e apresentar desenhos teóricos paralelos e/ ou complementares no sentido de melhor elucidar questões relacionadas à sustentabilidade, desenvolvimento e gestão. Tal avanço segue a necessidade de aplicar a compreensão da relação homem, meio ambiente e sociedade ante à possibilidade da preservação da vida, menor degradação do meio ambiente e atuação da gestão na promoção de organizações com amparo na atenção às problemáticas ambientais, sociais e humanas.

Com efeito, argumenta-se que o suporte teórico não é exaustivo ao campo das competências gerenciais e do desenvolvimento sustentável, não se podendo, portanto, extrapolar a relação entre esses conceitos no sentido de uma teoria final sobre competências gerenciais favoráveis ao desenvolvimento sustentável. Por isso, sugere-se a ampliação do quadro teórico de referência, bem como desenho de ações vinculadas às dimensões apreendidas. Assim, pode-se agregar a contribuição do estudo às situações concretas de trabalho que podem suscitar ao administrador/gestor caminhos favoráveis ao desenvolvimento sustentável.

Para tanto, considerar que competências gerenciais podem contribuir com um futuro mais sustentável também encontra respaldo na ideia da reflexão coletiva para superação dos problemas futuros, amparada pela concepção de estudos prospectivos (Shcenatto et al., 2011, Yoshida, 2011), em função da tomada de decisão que confere ampla responsabilidade aos administradores/gestores em promover e sustentar um desenvolvimento caracterizado como sustentável. Já para o campo da ciência, a lógica desenvolvida assenta na ampliação de pesquisas no âmbito da sustentabilidade nos processos formativos, em especial, na definição de competências que compreendam a complexidade dos diferentes sistemas, na exploração de opções futuras, criação de visões de sustentabilidade e no desenvolvimento de estratégias confiáveis.

Nesse sentido, o desafio assumido na pesquisa apresentada, supõe que competências gerenciais favoráveis ao desenvolvimento sustentável se tornam necessárias face à busca de metodologias e técnicas, ou inovações, que possam sustentar práticas sustentáveis. Assim, essas inovações envolvem a interação de corporações, instituições governamentais e de conhecimento e agentes diversos no sentido de promover inovações úteis para o atingimento do desenvolvimento sustentável (Nascimento, Mendonça \& Cunha, 2012).

\section{REFERÊNCIAS}

Alves Filho, L. da C. \& Silva, A. B. Muzzio, H. (2019). Criatividade e desenvolvimento de competências gerenciais em empresas de base tecnológica. Economia e Gestão, 19 (52).

Berry, J. W. (1997). Immigration, acculturation and adaptation. Applied psychology: An International Review, 46 (1), 5-30.

Bizarria, F. P. A., Oliveira, P. G., Gomes, N. dos R., Santos, S. L. C. \& Barbosa, F. L. B. (2020). Categorias de análise sobre Competências Gerenciais para o Desenvolvimento Sustentável. Brazilian Journal of Developmente, 6 (7), 44806-44828.

Boog, G. G. (1991) O desafio da competência: como enfrentar as dificuldades do presente e preparar sua empresa para o futuro. São Paulo: Editora Best Seller.

\begin{tabular}{|l|l|l|l|l|l|}
\hline Rev. Gest. Soc. Ambient. & São Paulo (SP) & v.15 & p.01-20 & e02646|2021. \\
\hline
\end{tabular} 
Bizarria, F. P. de A., Barbosa, F. L. S., Santos, S. L. C. dos, \& Oliveira, P. G. (2021). Análise Confirmatória de Competências Gerenciais para o Desenvolvimento Sustentável.

Borges-Andrade, J. E. \& Bittencourt, A. V. (Orgs.) (2004). Psicologia, Organizações e Trabalho no Brasil. Porto Alegre: Artmed.

Borges, F. Q., Chotoe, J. R. \& Varela, L. B. (2014). Administração energética e análise tendencial de custos econômicos de fontes de geração no Brasil. Revista de Administração da UNIMEP, 12 (3), 100-121, set./dez.

Brandão, H., Borges-Andrade, J. \& Guimarães, T. (2012). Desempenho organizacional e suas relações com competências gerenciais, suporte organizacional e treinamento. $R$. Adm., São Paulo, 47 (4), 523- 539, out./dez.

Brandão, H. P., Borges-Andrade, J. E., Freitas, I. A. \& Vieira, F. T. (2010). Desenvolvimento e estrutura interna de uma escala de competências gerenciais. Revista Psicologia: Teoria e Pesquisa, Brasília, 26 (1), 43-54, jan./mar.

Byrne, B. M. (2010). Structural Equation Modeling with AMOS: Basic Concepts, Applications, and Programming. 2.ed. New York: Routledge - Taylor \& Francis G.

Chabowski, B. R., Mena, J. A. \& Gonzalez-Padron, T. L. (2011). The structure of sustainability research in marketing, 1958-2008: a basis for future research opportunities. Journal of the Academy of Marketing Science, 39 (1), 55-70.

Collis, J. \& Hussey, R. (2005). Pesquisa em Administração. 2a. Ed. Ed. Bookman, São Paulo.Corrar, L., Paulo, E. \& Dias Filho, J. (2014). Análise Multivariada para os Cursos de Administração, Ciências Contábeis e Economia. São Paulo: Atlas, 1 Ed. 7 Reimpressão.

Demajorovic, J. \& Martão, S. D. (2014). Competências e inserção profissional de administradores em sustentabilidade. Pretexto, Belo Horizonte, 15, 48-66.

Dzhengiz, T., \& Niesten, E. (2019). Competences for Environmental Sustainability: A Systematic Review on the Impact of Absorptive Capacity and Capabilities. Journal of Business Ethics, 162(4), 881-906. https://doi.org/10.1007/s10551-019-04360-Z

Durand, T. (2000). L'alchimie de la compétence. Revue Française de Gestion, 127, 84-102, jan./fev.

Dutra, J. S. (2004). Competências: Conceitos e instrumentos para a gestão de pessoas na empresa moderna. São Paulo: Atlas.

Fanelli, S., Lanza,G., Enna,C., \& Zangrandi, A. (2020). Managerial competences in public organisations: the health care professionals' perspective. BMC Health Services Research, 20(1), 19. https://doi.org/10.1186/s12913-020-05179-5

Ferreira, J. M. P. \& Paiva, K. M. de (2017). Competências Gerenciais dos Coordenadores de Cursos de Instituições Privadas de Ensino Superior de Fortaleza, CE. RACE, 16 (2), 681-702, maio/ago.

\begin{tabular}{|l|l|l|l|l|l|}
\hline Rev. Gest. Soc. Ambient. & São Paulo (SP) & v.15 & p.01-20 & e02646 & 2021. \\
\hline
\end{tabular} 
Bizarria, F. P. de A., Barbosa, F. L. S., Santos, S. L. C. dos, \& Oliveira, P. G. (2021). Análise Confirmatória de Competências Gerenciais para o Desenvolvimento Sustentável.

Fleury, M. T. L. \& Fleury, A. (2001). Construind o o conceito de competência. RAC - Revista de Administração Contemporânea, 5, 183-196, Ed. Especial.

Fleury, M. T. L. \& Fleury, A. (2004). Competitive strategies and core competencies: Perspective for the internationalisation of industry in Brasil, Integrated Manufacturing Systems, Kempston, 14 (1), 16-25.

Freitas, P. F. P. \& Odelius, C. C. (2018). Competências gerenciais: uma análise de classificação em estudos empíricos. Cadernos Ebape.Br, 16 (1).

Freitas, P. (2016). Relações entre competências gerenciais de líderes de grupos de pesquisa e resultados alcançados. 209f. Dissertação (Mestrado em Administração) — Universidade de Brasília. Brasília: UnB.

Froehlich, C. (2014). Publicações internacionais sobre sustentabilidade: uma revisão de artigos com o uso da técnica de análise de conteúdo qualitativa. Revista de Administração da UFSM, 7 (2), 178195.

Gallon, A. V., Souza, F. C., Rover, S. \& Bellen, H. M. V. (2008). Um estudo longitudinal da produção científica em administração direcionada à temática ambiental. Revista Alcance, 15 (1), 81101.

Ghoshal, S. (2005). Bad Management Theories Are Destroying Good Management Practices. Academy of Management Learning \& Educations, 4 (1), 71-91.

Gonçalves-Dias, S. L. F., Herrera, C. B. \& Cruz, M. T. de S. (2013). Desafios (e dilemas) para inserir "sustentabilidade" nos currículos de administração: um estudo de caso. RAM - Revista de Administração Mackenzie, 14 (3), 119-153.

Gondim, S. M. G. (2002). Perfil profissional e mercado de trabalho: Relação com a formação acadêmica pela perspectiva de estudantes universitários. Estudos de Psicologia, 7 (2), 299-309.

Guimaraes, R. \& Fontoura, Y. (2012). Desenvolvimento sustentável na Rio+20: discursos, avanços, retrocessos e novas perspectivas. Cad. EBAPE.BR, Rio de Janeiro, 10 (3), 508-532, set.

Hair Jr., William, B., Babin, B. \& Anderson, R. E. (2009). Análise multivariada de dados. 6.ed. Porto Alegre: Bookman.

Hassan, A. (2020). Managerial Competencies Required to Achieve Sustainable Development Projects: A Proposed Model for Managers. Environmental Management and Sustainable Development, vol. 9, no. 3.

Froehlich, C. (2014). Publicações internacionais sobre sustentabilidade: uma revisão de artigos com o uso da técnica de análise de conteúdo qualitativa. Revista de Administração da UFSM, 7 (2), 178195. 
Bizarria, F. P. de A., Barbosa, F. L. S., Santos, S. L. C. dos, \& Oliveira, P. G. (2021). Análise Confirmatória de Competências Gerenciais para o Desenvolvimento Sustentável.

Froehlich, C., Mello, D. \& Engelman, R. (2017). Inovação e sustentabilidade: um olhar sobre a produção científica publicada em eventos da Associação Nacional de Pós-Graduação e Pesquisa em Administração. Revista Gestão e Desenvolvimento, Novo Hamburgo, 14 (2), 19-32.

International Labour Organization (2020, 07 de abril). ILO Monitor: Covid-19 and the world of work. Second Edition. Updated estimates and analysis. Genebra, Switzerland.

Jabbour, C. J. C., Santos, F. C. A. \& Barbieri, J. C. (2008). Gestão ambiental empresarial: um levantamento da produção científica brasileira divulgada em periódicos da área de administração entre 1996 e 2005. Rev. Adm. Contemp., Curitiba, 12 (3), 689-715.

Le Boterf, G. (2003). Desenvolvendo a competência dos profissionais. Porto Alegre: Artmed.

Leonidou, C. N. \& Leonidou, L. C. Research into environmental marketing/ management: a bibliographic analysis. European Journal of Marketing, v. 45, n. 1/2, p. 68-103, 2011.

Lizuka, E. S. \& Peçanha, R. S. (2014). Análise da produção científica brasileira sobre sustentabilidade entre 2008 e 2011. Revista de Gestão Ambiental e Sustentabilidade, 3 (1), 1-17.

Luca, M. M. M., Cardoso, V. I. C., Vasconcelos, A. C. \& Pontes, A. B. (2014). Análise da produção científica referente à temática de sustentabilidade em pesquisas da Administração. Administração: Ensino e Pesquisa, 15 (3), 469-469.

Malhotra, N. K. (2012). Pesquisa de Marketing. Uma orientação aplicada. Tradução de Lene Belon Ribeiro, Monica Stefani. 6. ed. Porto Alegre: Bookman.

Marôco, J. (2014). Análise de Equações Estruturais: fundamentos teóricos, software \& aplicações. Report number, Pêro Pinheiro, 2 Ed.

Hansen, E. G., Grosse-Dunker, F. \& Reichwald, R. (2009). Sustainability innovation cube: a framework to evaluate sustainability-oriented innovations. International Journal of Innovation Management, 13 (4), 683-713.

Prahalad, C. K. \& Hamel, G. The Core Competence of the Corporation. Harvard Business Review, p. 3- 15, May/June, 1990.

Pospichil, B. C., Froehlich, C., Nodari, C. H., Schmidt, S. \& Machado, R. E. (2020). The Contribution of the Dynamic Capabilities to Promote Sustainability in Industrial and Service Companies. Revista Base, vol. 17, no. 2, pp. 180-210.

Quinn, R. E. et al. (2003). Competências gerenciais: princípios e aplicações. 3a ed. Rio de Janeiro (RJ): Elsevier.

Richardson, R. J. (1999). Pesquisa social: métodos e técnicas. São Paulo: Atlas.

Rosa, F. \& Ensslin, S. R. (2007). Tema a "gestão ambiental" em eventos científicos: um estudo exploratório nos eventos avaliados segundo critério qualis da Capes. In: ENCONTRO NACIONAL

\begin{tabular}{|l|l|l|l|l|l|}
\hline Rev. Gest. Soc. Ambient. & São Paulo (SP) & v.15 & p.01-20 & e02646 & 2021. \\
\hline
\end{tabular} 
Bizarria, F. P. de A., Barbosa, F. L. S., Santos, S. L. C. dos, \& Oliveira, P. G. (2021). Análise Confirmatória de Competências Gerenciais para o Desenvolvimento Sustentável.

SOBRE GESTÃO EMPRESARIAL E MEIO AMBIENTE, 9., 2007, Curitiba. Anais [...] Curitiba: Unicenp.

Ruas, R., Antonello, C. S. \& Boff, L. H. (2005). Os novos horizontes da gestão: aprendizagem organizacional e competências. Porto Alegre: Bookman.

Sachs, I. (2007). Rumo à ecossocioeconomia: teoria e prática do desenvolvimento [Org. Paulo Freire Vieira]. São Paulo: Cortez.

Sachs, I. (2009). Caminhos para o desenvolvimento sustentável. Rio de Janeiro: Garamond.

Schubert, A. \& Láng, I. (2005). The literature after math of the brundtland report 'our common future'. A scientometric study based on citations in science and social science journals. Environment, Development and Sustainability, 7 (1), 1-8.

Schwartz, S. H. (1992). Universals in the context and structure of values: theoretical advances and empirical tests in 20 countries. In M. Zanna (Org.), Advances in experimental social psychology (vol. 25, pp. 1- 65). Orlando: Academic Press.

Silveira, L. M. \& Petrini, M. (2018). Desenvolvimento Sustentável e Responsabilidade Social Corporativa: uma análise bibliométrica da produção científica internacional. Gest. Prod., São Carlos, 25 (1), 56-67.

Souza, M. T. S. \& Ribeiro, H. C. M. (2013). Sustentabilidade ambiental: uma meta-análise da produção brasileira em periódicos de administração. Rev. Adm. Contemp., Curitiba, 17 (3), 368-396.

Spencer, L. M. \& Spencer, S. M. (1993) Competence at work: models for superior performance. New York: John Wiley \& Sons.

Springett, D. (2005). Education for sustainability in the business studies curriculum: a call for a critical agenda. Business Strategy and the Environment, 14, 146-159.

Srivastava, D. K. (2010). "Perspectives on Corporate Social Responsibility (CSR): A Case Study of the Tata Group of Companies", in Gupta, A., Ethics, Business and Society: Managing Responsibly, SAGE Publications.

Streiner D. L. (2003). Being inconsistent about consistency: When coeficiente alpha does and doesn't matter. J Pers Assess. 80(3), 217-22

Zarifian, P. (2001). Objetivo competência: por uma nova lógica. São Paulo: Atlas.

\begin{tabular}{|l|l|l|l|l|l|}
\hline Rev. Gest. Soc. Ambient. & São Paulo (SP) & v.15 & p.01-20 & e02646 & 2021. \\
\hline
\end{tabular} 